\title{
Multicomponent non-aqueous electrolytes for high temperature operation of supercapacitors
}

\author{
(C) Svetlana V. Stakhanova, ${ }^{1,2+}$ Mikhail V. Astakhov, ${ }^{1 *}$ Ludmila A. Puntusova, ${ }^{1}$ \\ Ruslan R. Galymzyanov, ${ }^{1}$ Ilya S. Krechetov, ${ }^{1}$ \\ Alexey V. Lisitsyn, ${ }^{1}$ and Natalia V. Sviridenkova ${ }^{1,2}$ \\ ${ }^{1}$ Physical Chemistry Division. National University of Science and Technology "MISiS". \\ Leninsky Ave., 6. Moscow, 119049. Russia. Phone: +7 (495) 638-46-64. \\ ${ }^{2}$ Analytical Chemistry Department. D. Mendeleev University of Chemical Technology of Russia. \\ Miusskaya Sq., 9. Moscow, 125047. Russia. Phone: +7 (495) 638-46-64. \\ E-mail: stakhanovasv@gmail.com
}

\begin{abstract}
*Supervising author; ${ }^{+}$Corresponding author Keywords: non-aqueous electrolyte, supercapacitor, tetraethylammonium tetrafluoroborate, propylene carbonate, ethylene carbonate.
\end{abstract}

\begin{abstract}
Multicomponent non-aqueous electrolytes based on cyclic carbonates and tetraethylammonium tetrafluoroborate have been developed for the operation of supercapacitors at elevated temperatures.

Propylene carbonate, which has a high dielectric constant and a high boiling point, was used as the main solvent of electrolytes. However, a significant drawback of propylene carbonate is its high viscosity, which leads to decrease in the electrical conductivity of electrolytes based on it compared to electrolytes based on acetonitrile.

To increase the electrical conductivity, an additional component was introduced into the electrolyte - a cosolvent with the necessary set of properties. When choosing cosolvents, two approaches were used. In the first case, to increase the dielectric permittivity of the liquid phase, ethylene carbonate having a higher dielectric constant than propylene carbonate was introduced into the electrolyte. This approach made it possible to significantly increase the electrical conductivity of the electrolyte and to achieve high resource stability of the supercapacitor. The values of the specific capacitance and energy of the supercapacitor with the introduction of ethylene carbonate in the electrolyte practically did not change. In the second case, butyl acetate, which has a low viscosity but has a moderate polarity and a sufficiently high boiling point, was used as a co-solvent. In this case, not only an increase in the electrical conductivity of the electrolyte was observed, but also a significant increase in the capacitive characteristics of the supercapacitor.

It is shown that the use of a mixture of cyclic carbonates and esters as a solvent in the composition of the electrolyte can increase its specific conductivity by $40 \%$, and the specific energy consumption of a supercapacitor by $20 \%$. The developed electrolytes provide long-term operation of supercapacitors both at room temperature and at elevated temperatures up to $80^{\circ} \mathrm{C}$.
\end{abstract}

\section{References}

[1] B.E. Conway. Electrochemical Supercapacitors: Scientific Fundamentals and Technological Applications. New York: Kluwer Academic/Plenum Publishers. 1999. 736c.

[2] E. Frackowiak, F. Beguin. Carbon materials for the electrochemical storage of energy in capacitors. Carbon. 2001. Vol.39. P.937-950.

[3] L.L. Zhang, X.S. Zhao. Carbon-based materials as supercapacitor electrodes. Chem. Soc. Rev. 2009. Vol.38. P.2520-2531.

[4] M.V. Astakhov, E.E. Kazenas, A.T. Kalashnik, A.A. Klimont, T.L. Lepkova, and S.V. Stakhanova. Preparftion of a flexible supercapacitor electrode materials based on modified carbon fiber. Butlerov Communications. 2016. Vol.47. No.9. P.128-133. DOI: 10.37952/ROI-jbc-02/16-47-9-128

[5] K. Hung. Wide temperature range operation supercapacitors from nanostructured activated carbon fabric. Journal of Power Sources. 2009. Vol.193. P.944-949.

[6] M.V. Astakhov, A.T. Kalashnik, E.E. Kazenas, T.L. Lepkova, V.V. Kozlov, and F.S. Tabarov. Development of carbon composite based on carbon fibers from viscose material for supercapacitor 
electrodes. Butlerov Communications. 2016. Vol.48. No.10. P.43-48. DOI: 10.37952/ROI-jbc-02/16-48$10-43$

[7] M.V. Astakhov, F.S. Tabarov, A.T. Kalashnik, A.A. Klimont, T.L. Lepkova, and D.E. Amelina. A new raw material to produce activated carbon as a material for electrodes of supercapacitors. Butlerov Communications. 2018. Vol.54. No.5. P.82-89. DOI: 10.37952/ROI-jbc-02/18-54-5-82

[8] S.V. Stakhanova, M.V. Astakhov, A.A. Klimont, I.S. Krechetov, A.T. Kalashnik, R.R. Galymzyanov and K.A. Semushin. Polyaniline composites based on porous fibrous carbon materials for supercapacitor electrode structures. Butlerov Communications. 2015. Vol.41. No.1. P.130-137. DOI: 10.37952/ROI-jbc$02 / 15-41-1-130$

[9] S.V. Stakhanova, M.V. Astakhov, A.A. Klimont, I.S. Krechetov, A.T. Kalashnik, R.R. Galymzyanov, O.V. Zaytseva, and N.V. Sviridenkova. Effect of oxygen-containing surface functional groups of carbon electrodes on the self-discharge of supercapacitors. Butlerov Communications. 2015. Vol.41. No.1. P.6773. DOI: $10.37952 / R O I-j b c-02 / 15-41-1-67$

[10] M.V. Astakhov, R.R. Galimzyanov, A.A. Klimont, I.S. Krechetov, M. Kundu, S.V. Stakhanova. Improved symmetric supercapacitive performance of binder-free pani/carbon fiber composites. Current Nanoscience. 2016. Vol.12. No.1. P.83-89.

[11] C. Zhong, Y. Deng, W. Hu. A review of electrolyte materials and compositions for electrochemical supercapacitors. Chemical Society Reviews. 2015. Vol.44. No.21. P.7484-7539.

[12] E. Perricone, M. Chamas, J.C. Leprêtre. Safe and performant electrolytes for supercapacitor. Investigation of esters/carbonate mixtures. Journal of Power Sources. 2013. Vol.239. P.217-224.

[13] N. Katayama, T. Kawamura, Y. Baba et al. Thermal stability of propylene carbonate and ethylene carbonate-propylene carbonate-based electrolytes for use in Li cells. Journal of Power Sources. 2002. Vol.109. No.2. P.321-326.

[14] A. Janes. Electrochemical Double Layer Capacitors Based on Propylene Carbonate Solution Operating from $-45^{\circ} \mathrm{C}$ to $100{ }^{\circ} \mathrm{C}$. Journal of the Electrochemical Society. 2014. Vol.161. P.A712-A717.

[15] M. Ue. Chemical capacitors and quaternary ammonium salts. Electrochemistry. 2007. Vol.75. No.8. P.565-572.

[16] M. Ue, K. Ida, S. Mori. Electrochemical Properties of Organic Liquid Electrolytes Based on Quaternary Onium Salts for Electrical Double-Layer Capacitors. Journal of the Electrochemical Society. 1994. Vol.141. No.11. P.2989-2996.

[17] M. Ue, M. Takeda, M. Takehara et al. Electrochemical properties of quaternary ammonium salts for electrochemical capacitors. Journal of the Electrochemical Society. 1997. Vol.144. No.8. P.2684-2688. 